\title{
Patient education to encourage graded exercise in chronic fatigue syndrome
}

\author{
2-year follow-up of randomised controlled trial
}

\author{
PAULINE POWELL, RICHARD P. BENTALL, FRED J. NYE \\ and RICHARD H. T. EDWARDS
}

\author{
Background An earlier trial \\ demonstrated good outcomes after I year \\ for patients with chronic fatigue syndrome \\ (CFS) who received an educational \\ intervention designed to encourage \\ graded activity.
}

Aims To determine 2-year outcomes for the same treated patients and the response to treatment of patients formerly in the control condition.

\section{Method Patients in the treatment groups ( $n=114$ ) were followed up at 2 years; 32 patients from the control group were offered the intervention after I year and were assessed I year later. \\ Assessments were the self-rated measures used in the original trial.}

\section{Results At 2 years 63 of the treated patients (55\%) no longer fulfilled trial criteria for CFS compared with 64 patients (56\%) at I year. Fourteen of 30 crossover patients (47\%) achieved a good outcome at I year and seven (23\%) no longer fulfilled criteria for CFS. \\ Conclusions Benefits of the intervention were maintained at 2 years. Delaying treatment is associated with reduced efficacy and required more intensive therapy.}

Declaration of interest None. Funding detailed in Acknowledgements.
A systematic review by Whiting et al (2001) found graded exercise and cognitivebehavioural therapy to be promising treatments for chronic fatigue syndrome. In a randomised controlled trial (Powell et al, 2001), patients received evidence-based physiological explanations for symptoms to encourage self-managed graded exercise and regulation of sleep in three different dosages (defined in terms of therapist time and follow-up telephone contacts). At 1year follow-up, treated patients showed significantly greater improvement in measures of physical functioning, fatigue, sleep and mood compared with an untreated control group, but no difference was found between the different dosages. The study reported here looked at the same patient groups to determine if these improvements were maintained after a further year, and whether treatment dosage affected longterm outcome. A third aspect of this study was to assess at 1 year the outcome of patients who had been in the 1-year trial control group and who then crossed over into the educational intervention.

\section{METHOD}

\section{Participants}

The original trial recruited 148 patients who fulfilled the Oxford criteria for chronic fatigue syndrome (Sharpe et al, 1991) from a chronic fatigue clinic and an infectious diseases out-patient clinic, and who scored below 25 on the physical functioning sub-scale of the 36-item Short Form Health Survey (SF-36; Ware \& Sherbourne, 1992). Participants were randomised into four groups. Patients were excluded if they were having further investigations, undertaking other treatments (with the exception of antidepressant therapy if taken at a constant dosage for at least 3 months without improvement), had a psychotic disorder, somatisation disorder, eating disorder or a history of substance misuse, or were non-ambulatory.

\section{Treatment interventions in the original study}

Patients in the control group received standard medical care comprising a medical assessment and a short information booklet that encouraged increased activity and positive thinking without explanation of symptoms. Active intervention groups received a medical assessment followed by evidence-based physiological explanations of symptoms that focused on physical deconditioning and sleep abnormalities. A home-based graded exercise programme was designed collaboratively with each patient and individualised to suit functional abilities. Once the patient was engaged in treatment, the role of predisposing and perpetuating psychosocial factors was discussed. The treatment rationale was supported by a comprehensive educational information pack which reiterated the verbal explanations offered.

Three dosages of treatment were compared. Patients in the minimum intervention group received two individual face-to-face sessions and monitored access to a telephone helpline that was reported with the trial; the telephone intervention group received an additional seven planned follow-up telephone calls; and the maximum intervention group received the minimum intervention plus an additional seven face-to-face treatment sessions. These sessions were used to reiterate the treatment rationale, discuss problems associated with graded exercise using motivational interviewing techniques (Miller \& Rollnick, 1991) and explore any relevant psychosocial factors. Self-reporting validated outcome measures were sent by post to the participants before randomisation, and 3 months, 6 months and 12 months after the start of treatment.

\section{Further assessments} and interventions in this study

For those who completed the treatment, a 2-year assessment of outcome was conducted using the same self-rated validated questionnaires used in the original study. Patients in the original control group were offered a similar educational intervention at the end of the 1-year trial period. This was delivered by the same therapist (P.P.) who had treated the patients in the original experimental groups. The former control 
group patients were not given a further medical assessment before participating in active treatment, which was a combination of telephone and face-to-face sessions similar to those offered to treatment patients in the original trial. The number of sessions was determined pragmatically on the basis of patient need and was allowed to exceed those given to the original treatment groups. Patients' 1-year control outcome assessments were used as their pre-treatment baseline measures. These measures were reassessed 1 year after the start of treatment.

\section{Assessments}

Primary outcomes were measured on the physical functioning sub-scale of the SF36 (range 10 to 30 , where 10 indicates maximum physical limitation including self-care, and 30 indicates ability to do vigorous sports) and the fatigue scale (Chalder et al, 1993; range 0-11, scores over 3 indicate excessive fatigue). The predetermined criterion of clinically significant improvement was a score of 25 or over or an increase of 10 or more in the baseline score on the physical functioning sub-scale of the SF-36. This is virtually equivalent to normal daily functioning for the UK general population (Garratt et al, 1993). The intention-to-treat mean score for physical functioning of the educational intervention patients at 1 year was 24.74. The comparable mean physical functioning score for the control group, used as a baseline measure before crossover into active treatment, was 16.94 .

Secondary outcome measures administered to both groups at the same time points included the Hospital Anxiety and Depression (HAD) scale (Zigmond \& Snaith, 1983; scores above 10 indicate caseness on each of the anxiety and depression sub-scales); a four-item sleep problem questionnaire (Jenkins et al, 1988; range $0-20$, where 0 indicates no sleep problems and 20 indicates maximum sleep problems); and a seven-point global impression of change score taken 1 year from trial entry and ranging from 'very much better' to 'very much worse' (Guy, 1976).

\section{Statistical analysis}

Analyses of the outcome data from both the 2-year assessment group and the crossover control group were carried out separately. In each case we used an intention-to-treat analysis and included all patients who were randomised into the original trial. Crossover analysis included all who accepted crossover treatment.

\section{RESULTS}

\section{Patient recruitment}

During the original trial, 19 patients from the active intervention groups were lost to follow-up (Powell et al, 2001); a further five patients were lost to follow-up at 2 years (two developed other medical conditions, one died by suicide and two were untraceable). The last values obtained from these patients were carried forward. Thirtytwo patients in the control group completed the original trial and were subsequently offered active treatment: 30 patients accepted. Five patients withdrew from treatment: one for medical reasons and four who could not comply with the intervention. The last outcome values obtained from these treatments were also carried forward.

The median number of telephone and face-to-face treatment sessions in the crossover intervention was 16 (minimum 1 , maximum 36). The mean duration of treatment was 40.8 weeks (minimum 1 week, maximum 1 year).

\section{Two-year outcome of original intervention patients}

Table 1 and Fig. 1 show the outcome measures at the original trial baseline assessment and at 1-year and 2-year follow-up. Repeated-measures analysis of variance (ANOVA) was used to compare the three treatment groups at each point. For physical functioning scores, there was no significant difference between the treatment groups $\left(F_{2,111}=0.47, \quad P=0.63\right)$

Table I Outcome measures of the three treatment groups at the original trial baseline assessment and at I-year and 2-year follow-up

\begin{tabular}{|c|c|c|c|c|c|c|}
\hline \multirow[t]{3}{*}{ Outcome measure } & \multicolumn{6}{|c|}{ Treatment group } \\
\hline & \multicolumn{2}{|c|}{$\begin{array}{l}\text { Minimum intervention } \\
\qquad(n=37)\end{array}$} & \multicolumn{2}{|c|}{$\begin{array}{c}\text { Telephone interven- } \\
\text { tion }(n=39)\end{array}$} & \multicolumn{2}{|c|}{$\begin{array}{l}\text { Maximum intervention } \\
\qquad(n=38)\end{array}$} \\
\hline & Mean & s.d. & Mean & s.d. & Mean & s.d. \\
\hline \multicolumn{7}{|c|}{ Physical functioning score (SF-36)' } \\
\hline Pre-treatment & 16.00 & 3.04 & 15.77 & 3.70 & 15.95 & 3.36 \\
\hline I year & 25.08 & 5.21 & 24.26 & 5.31 & 24.89 & 4.70 \\
\hline 2 years & 24.11 & 5.94 & 23.64 & 6.39 & 25.45 & 4.72 \\
\hline \multicolumn{7}{|l|}{ Fatigue score $^{2}$} \\
\hline Pre-treatment & 10.35 & I.II & 9.92 & 2.17 & 10.24 & 1.17 \\
\hline I year & 3.24 & 4.40 & 3.46 & 4.34 & 3.11 & 3.85 \\
\hline 2 years & 4.46 & 4.78 & 3.59 & 4.69 & 2.84 & 3.67 \\
\hline \multicolumn{7}{|c|}{ Depression score $(H A D)^{3}$} \\
\hline Pre-treatment & 9.27 & 3.73 & 9.03 & 3.75 & 9.03 & 3.61 \\
\hline I year & 4.24 & 3.73 & 4.62 & 4.31 & 4.21 & 3.91 \\
\hline 2 years & 5.11 & 5.12 & 4.77 & 4.67 & 4.08 & 4.33 \\
\hline \multicolumn{7}{|c|}{ Anxiety score (HAD) ${ }^{4}$} \\
\hline Pre-treatment & 10.62 & 4.48 & 10.03 & 5.02 & 10.21 & 4.45 \\
\hline I year & 7.14 & 4.04 & 6.51 & 4.27 & 7.7I & 4.79 \\
\hline 2 years & 7.65 & 4.78 & 7.03 & 5.07 & 7.13 & 4.47 \\
\hline \multicolumn{7}{|c|}{ Sleep problems score ${ }^{5}$} \\
\hline Pre-treatment & 12.43 & 4.85 & 13.53 & 4.43 & 13.03 & 4.98 \\
\hline I year & 6.70 & 5.18 & 8.56 & 5.44 & 7.13 & 4.81 \\
\hline 2 years & 7.62 & 5.30 & 8.15 & 5.59 & 7.92 & 5.50 \\
\hline
\end{tabular}

HAD, Hospital Anxiety and Depression scale; SF-36, 36 -item Short Form Health Survey.

I. Range $10-30$, where 10 is maximum limitation, 30 is no limitation.

2 Range $0-\mathrm{II}$, score $>3$ indicates excessive fatigue.

3. Range $0-2 \mathrm{I}$, score $>10$ indicates depression.

4. Range $0-21$, score $>10$ indicates anxiety.

5. Range $0-20$, where 20 indicates maximum disturbance. 


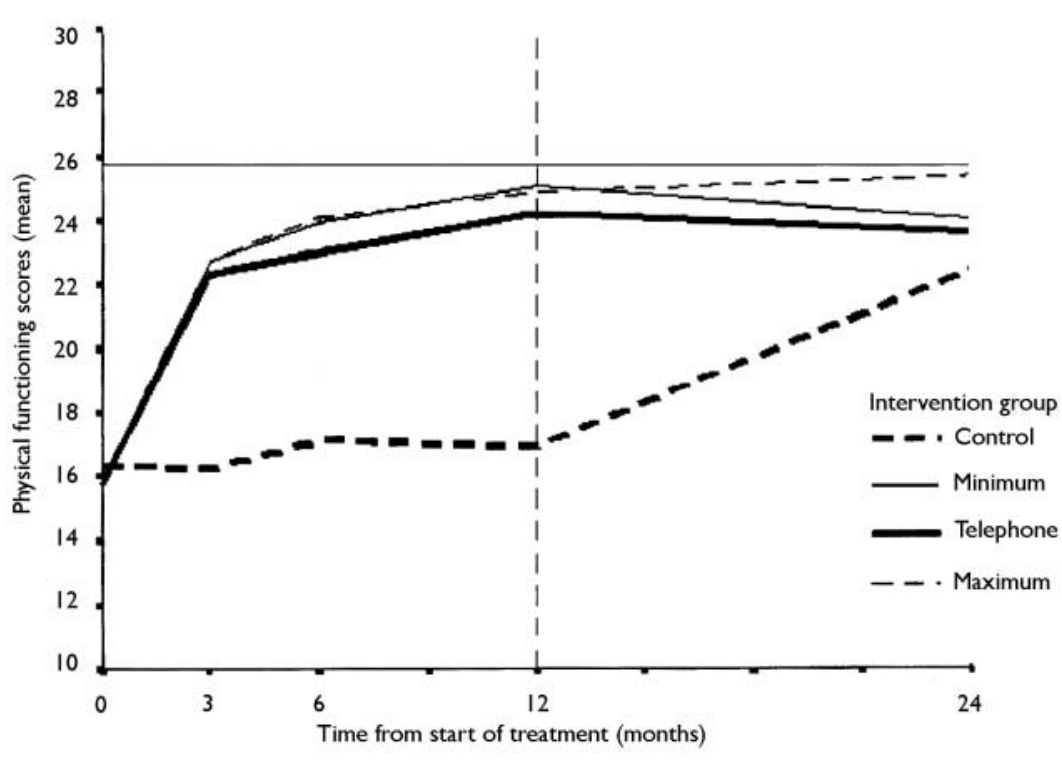

Fig. I Mean scores for physical functioning measured on the 36-item Short Form Health Survey (10, maximum limitation; 30, no limitation) for the three treatment groups and the control group. The vertical reference line at 12 months indicates the point at which patients in the control group crossed over into active treatment. The horizontal reference line indicates the mean physical functioning score for the UK general population (Garratt et al, 1993).

and the group $\times$ treatment interaction was also non-significant $\left(F_{4,222}=9.55\right.$, $P=0.51$ ). However, there was a highly significant difference between scores at the three time points $\left(F_{2,222}=248.58\right.$, $P<0.001)$. Bonferroni tests confirmed that there was no significant difference between scores at 1 year and 2 years, but that scores at both time points were improved compared with baseline $(P<0.001$ for each comparison).

For fatigue scores an identical pattern was observed, with a significant effect for time points $\left(F_{2,222}=227.30, P<0.001\right)$ but no significant group effect $\left(F_{2,111}=0.45\right.$, $P=0.64) \quad$ or interaction $\quad\left(F_{4,222}=8.34\right.$, $P=0.36)$. Again, scores at both follow-up points were improved compared with those at baseline $(P<0.001$ for each comparison) but there was no significant difference between scores at the two follow-up points.

Table 2 shows the number of patients from the different educational interventions who achieved a clinically significant outcome and/or no longer fulfilled trial criteria for the condition at the 1-year and 2-year follow-up assessments. On the clinical global impression scale, 70 of 90 patients $(78 \%)$ who completed the educational intervention reported being 'very much better' or 'much better' at 2 years compared with 80 of $95(84 \%)$ at 1 year.

\section{Outcome of former control patients after I year of active treatment}

Table 3 and Fig. 1 show the outcome measures at the pre-treatment assessment and 1-year follow-up for patients who crossed over into active treatment. Repeated-measures ANOVA was used to compare the patients at baseline during the original trial, the pre-treatment assessment at the end of the control period, and 1 year after the end of treatment. On the physical functioning scale, a significant effect was found for time $\left(F_{2,58}=23.65\right.$, $P<0.001)$. Bonferroni tests revealed that this was accounted for by significant differences between scores after treatment and at both pre-treatment assessments $(P<0.001$ for each comparison) but that there was no significant difference between scores at the original trial baseline and pre-treatment assessments. A similar pattern was observed in the fatigue scores of these patients, with a significant effect for time $\left(F_{2,58}=22.76, P<0.001\right)$ accounted for entirely by differences between scores at the final follow-up point and both pretreatment assessments $(P<0.001$ for each comparison). At the end of treatment, almost a half of the crossover patients (14 out of $30 ; 47 \%$ ) achieved a clinically significant outcome; almost a quarter no longer fulfilled the trial criteria for chronic fatigue syndrome (7 out of 30 ; $23 \%)$; and more than two-thirds of those who completed the educational intervention (17 out of $25 ; 68 \%)$ reported being 'very much better' or 'much better' on the global assessment of outcome.

\section{Comparison of outcomes between the original treatment groups and the crossover group}

To assess the relative responsiveness to treatment of the control group compared with the original treatment groups, oneway ANOVAs were calculated for the primary assessment measures taken from each group 1 year after their treatment had commenced (which was 1 year after inception in the case of the originally treated groups and 2 years after inception for the control group). In the case of physical functioning scores, no difference was observed between the groups $\left(F_{3,140}=1.49, P=0.22\right)$. However, a significant difference was observed for fatigue scores $\left(F_{3,140}=3.41, P<0.02\right)$ which was accounted for by better scores in the minimum and maximum original treatment groups (Bonferroni $P<0.05$ for each comparison) compared with the crossover patients. There was a significant difference between the number of patients who no longer met the trial criteria for chronic fatigue syndrome $\left(\chi^{2}=10.25, P<0.02\right)$, but no significant difference was observed in the proportion of patients achieving a clinically significant outcome $\left(\chi^{2}=5.37, P=0.15\right)$.

\section{DISCUSSION}

\section{Maintenance of gains at 2-year follow-up}

Patients who had received evidence-based physiological explanations for the symptoms of chronic fatigue syndrome to encourage graded exercise and regulate sleep maintained improvements at 2 years. Despite apparent trends across most measures for a slight worsening of outcome in the minimum intervention group and, if anything, a slight further improvement in the maximum intervention group, none of these differences approached significance. One patient who had received treatment died by suicide in the extended follow-up period. It seems unlikely that this was an adverse reaction to the treatment programme. At the original 1-year follow-up point this patient had made no improvement on any of the main outcome measures 
Table 2 Patients from the different educational intervention groups who achieved a clinically significant outcome and/or no longer fulfilled trial criteria for chronic fatigue syndrome at I-year and 2-year follow-up

\begin{tabular}{|c|c|c|c|c|c|c|}
\hline \multirow[t]{3}{*}{ Outcome } & \multicolumn{6}{|c|}{ Treatment group } \\
\hline & \multicolumn{2}{|c|}{$\begin{array}{l}\text { Minimum intervention } \\
\qquad(n=37)\end{array}$} & \multicolumn{2}{|c|}{$\begin{array}{c}\text { Telephone } \\
\text { intervention }(n=39)\end{array}$} & \multicolumn{2}{|c|}{$\begin{array}{l}\text { Maximum interventior } \\
\qquad(n=38)\end{array}$} \\
\hline & $n$ & (\%) & $n$ & (\%) & $n$ & (\%) \\
\hline \multicolumn{7}{|c|}{ Clinically significant outcome' } \\
\hline At I year & 26 & $(70)$ & 27 & $(69)$ & 26 & $(68)$ \\
\hline At 2 years & 20 & $(54)$ & 23 & (59) & 26 & (68) \\
\hline \multicolumn{7}{|c|}{ No longer fulfilled trial criteria ${ }^{2}$} \\
\hline At I year & 21 & (57) & 22 & (56) & 21 & (55) \\
\hline At 2 years & 17 & $(46)$ & 22 & (56) & 24 & (63) \\
\hline
\end{tabular}

SF-36; 36 -item Short Form Health Survey.

I. Achieving an end score $>24$ or improving 10 points on physical functioning sub-scale of SF-36.

2. Physical functioning score $>24$, fatigue score $<4$.

and was showing evidence of serious affective symptoms. Prior to killing himself he was under psychiatric care.

\section{Follow-up of control patients after I year of active treatment}

Patients who had been in the no-treatment control group for 1 year and then crossed

Table 3 Outcome measures at the pre-treatment assesment and at I-year follow-up for patients who crossed over into active treatment $(n=30)$

\begin{tabular}{|c|c|c|}
\hline \multirow[t]{2}{*}{ Outcome measure } & \multicolumn{2}{|c|}{ Score } \\
\hline & Mean & s.d. \\
\hline \multicolumn{3}{|c|}{ Physical functioning (SF-36)' } \\
\hline Pre-treatment & 16.32 & 3.36 \\
\hline I year & 22.47 & 7.02 \\
\hline \multicolumn{3}{|l|}{ Fatigue score ${ }^{2}$} \\
\hline Pre-treatment & 10.62 & 0.74 \\
\hline I year & 6.07 & 4.60 \\
\hline \multicolumn{3}{|l|}{ Depression (HAD) ${ }^{3}$} \\
\hline Pre-treatment & 10.35 & 4.09 \\
\hline I year & 8.37 & 5.75 \\
\hline \multicolumn{3}{|l|}{ Anxiety (HAD) ${ }^{4}$} \\
\hline Pre-treatment & 11.18 & 4.65 \\
\hline I year & 9.17 & 4.80 \\
\hline \multicolumn{3}{|l|}{ Sleep problems ${ }^{5}$} \\
\hline Pre-treatment & 12.79 & 4.76 \\
\hline I year & 10.07 & 6.06 \\
\hline
\end{tabular}

HAD, Hospital Anxiety and Depression Scale; SF-36,

36-item Short Form Health Survey.

I. Range $10-30$, where 10 is maximum limitation, $\mathbf{3 0}$ is

no limitation.

2 Range 0 -II, score $>3$ indicates excessive fatigue.

3. Range $0-2 \mathrm{l}$, score $>10$ indicates depression.

4. Range $0-21$, score $>10$ indicates anxiety.

5. Range $0-20$, where 20 indicates maximum

disturbance. over into active treatment were judged by the therapist to require more sessions over a longer period. Although this could be seen as evidence that treatment was harder to implement following a delay, the treatments delivered in the original treatment arms were constrained in length, and it is possible that the therapist would have chosen to extend these interventions if allowed to do so. However, there was evidence that the crossover patients showed less response on the measure of fatigue than the originally treated patients and were also less likely to recover as defined by the trial criteria for chronic fatigue. Although we found no relationship between duration of illness and outcome in our previous analysis of the 1-year follow-up data (Bentall et al, 2002), others have found an association between these variables (Clark et al, 1995; Vercoulen et al, 1996). Therefore, the possible relative unresponsiveness of the crossover patients might be due to the duration of illness, or the psychological effects of being placed in a waiting group.

\section{Consistency with previous findings}

Our findings support the long-term efficacy of treatments for chronic fatigue syndrome that incorporate graded exercise, including cognitive-behavioural therapy (Bonner et al, 1994; Deale et al, 2001). The effectiveness of such treatments may reflect the way in which they directly address physiological factors that can perpetuate the condition. Although there is no evidence of consistent pathological changes in chronic fatigue syndrome, there is evidence of a disturbance in bodily functioning involving cardiovascular and muscular deconditioning (Edwards et al, 1994; De Lorenzo et al, 1998). There is also evidence of sleep abnormalities (Morriss et al, 1997), mild cortisol deficiency (Demitrack et al, 1991) and desynchronisation of circadian rhythms (Williams et al, 1996) in patients with the syndrome. In the absence of an appropriate explanation, the subsequent symptoms can be misinterpreted as signs of an underlying pathological condition leading to reduced activity and chaotic sleep patterns, which perpetuate the syndrome. Our finding that the provision of physiological explanations for symptoms is associated with improved patient outcome is consistent with previous research. Patients have a basic physical conception of the body and its functions (Mabeck \& Olesen, 1997); consequently, physical explanations for the causal mechanism of symptoms can lead to reattribution and are empowering in the self-management of illness (Salmon et al, 1999). Indeed, the vast majority of patients who completed treatment in the original trial (Powell et al, 2001) reported that the physical explanations convinced them to carry out graded exercise and regulate chaotic sleep patterns; furthermore, they reported that they would recommend an educational intervention to other people with chronic fatigue syndrome.

\section{Limitations of this study}

This study has several limitations. Patients who withdrew from treatment in the original trial were not followed up and, although in the analysis their last values were carried forward, it would have been better if we had been able to obtain patients' actual outcome scores. There was no control comparison for 2-year followup of the treated patients. However, in view of the reduced efficacy of treatment when delivered after a 1-year wait, it would have been neither desirable nor ethically possible to justify a 2-year control period without treatment. Patient outcome was assessed by self-report measures, and it would have been helpful in addition to use objective measures of physiological exercise. Although the comparison of the crossover patient group with the original treatment group involved confounded time points, it is unlikely that this could explain the findings. No economic analysis was performed. 


\section{ACKNOWLEDGEMENT}

This research was supported by a grant from the Linbury Trust.

\section{REFERENCES}

Bentall, R. R., Powell, P., Nye, F. J., et al (2002) Predictors of response to treatment for chronic fatigue syndrome. British Journal of Psychiatry, 18I, 248-252.

Bonner, D., Ron, M., Chalder, T., et al (1994) Chronic fatigue syndrome: a follow up study. Journal of Neurology, Neurosurgery and Psychiatry, 57, 617-621.

Chalder, T., Berelowitz, G., Pawlikowska, T., et al (1993) Development of a fatigue scale. Journal of Psychosomatic Research, 37, 147-153.

Clark, M., Katon, W., Russo, J., et al (1995) Chronic fatigue: risk factors for symptom persistence in a two and a half year follow-up study. American Journal of Medicine, 98, I87- 195.

Deale, A., Chalder, T., Marks, I., et al (200I) Longterm outcome of cognitive behavior therapy versus relaxation therapy for chronic fatigue syndrome: a 5 -year follow-up study. American Journal of Psychiatry 158, 2038-2042.

De Lorenzo, F., Xiao, H., Mukherjee, M., et al (1998) Chronic fatigue syndrome: physical and cardiovascular deconditioning. Quarterly Journal of Medicine, $\mathbf{9 1}$, 475-481.

Demitrack, M., Dale, J., Straus, S., et al (1991) Evidence for impaired activation of the hypothalamicpituitary-adrenal axis in patients with chronic fatigue syndrome. Journal of Clinical Endocrinology and Metabolism, 73, 1224-1234.

Edwards, R., Clague, J., Gibson, H., et al (1994) Muscle metabolism, histopathology, and physiology in chronic fatigue syndrome. In Chronic Fatigue Syndrome (ed. S. Straus), pp. 24I-26I. New York: Marcel Dekker.

Garratt, A., Ruta, D., Abdalla, M., et al (1993) The SF36 health survey questionnaire: an outcome measure suitable for use within the NHS? BMI, 306, 1440-1444.

Guy, w. (1976) Clinical Global Impressions. In ECDEU Assessment Manual for Psychopharmacology, pp. 218-222. Rockville, MD: National Institute of Mental Health.

Jenkins, D., Stanton, B., Niemcryk, S., et al (1988) A scale for the estimation of sleep problems in clinical research. Journal of Clinical Epidemiology, 4I, 313-321.

Mabeck, C. \& Olesen, F. (1997) Metaphorically transmitted diseases. How do patients embody medical explanations? Family Practitioner, 14, 27I-278.

Miller, W. \& Rollnick, S. (199I) Motivational Interviewing. New York: Guilford Press.

\section{CLINICAL IMPLICATIONS}

- Providing patients with physiological explanations of symptoms of chronic fatigue syndrome to encourage graded exercise produces long-term benefits in outcome.

- Delay in treatment is associated with reduced treatment efficacy.

- It is possible that patients placed in waiting-list control groups are adversely affected by being assigned to this condition. This effect could bias clinical trial results and needs to be studied in more detail.

\section{LIMITATIONS}

Patients who withdrew from treatment in the original trial were not followed up.

- There was no control comparison group for 2-year follow-up of treated patients.

- Comparison of the crossover group with the original treatment group involved confounded time points.

PAULINE POWELL, PhD, RICHARD P. BENTALL, PhD, FRED J. NYE, MD, FRCP, RICHARD H. T. EDWARDS, MB, PhD, FRCP, Department of Psychology, University of Manchester, UK

Correspondence: Professor Richard Bentall, Department of Psychology, University of Manchester, Oxford Road, Manchester MI3 9PL,UK. E-mail: bentall@psy.man.ac.uk

(First received 27 February 2003, final revision 25 June 2003, accepted 30 July 2003)

Morriss, R., Wearden, A. \& Battersby, L. (1997) The relation of sleep difficulties to fatigue, mood and disability in chronic fatigue syndrome. Journal of Psychosomatic Research, 42, 597-605.

Powell, P., Bentall, R., Nye, F., et al (200I) Randomised controlled trial of patient education to encourage graded exercise in chronic fatigue syndrome. $B M$, 322, 387-390.

Salmon, P., Peters, S. \& Stanley, I. (1999) Patients' perceptions of medical explanations for somatisation disorders: qualitative analysis. BMJ, 318, 372-376.

Sharpe, M., Archard, L., Banarvala, J., et al (1991) A report - chronic fatigue syndrome: guidelines for research. Journal of the Royal Society of Medicine, $\mathbf{8 4}$ || $8-12 \mid$

Vercoulen, J., Swanink, C., Fennis, J., et al (1996)

Prognosis in chronic fatigue syndrome: a prospective study on the natural course. Journal of Neurology, Neurosurgery and Psychiatry, 60, 489-494.

Ware, J. \& Sherbourne, C. (1992) The MOS 36-item short form health survey (SF36). Medical Care, 30, 473483.

Whiting, P., Bagnall, A., Sowden, A., et al (200I) Interventions for the treatment and management of chronic fatigue syndrome: a systematic review. JAMA, 286, 1360-1388.

Williams, G., Piromohamed, J., Minors, D., et al (1996) Dissociation of body-temperature and melatonin secretion circadian rhythms in patients with chronic fatigue syndrome. Clinical Physiology, 16, 327-337.

Zigmond, A. \& Snaith, R. (1983) The Hospital Anxiety and Depression Scale. Acta Psychiatrica Scandinavica, 67, 361-370. 